\title{
Grain Structure Evolution during Friction-Stir Welding
}

\author{
S. Mironov ${ }^{1,2 *}$, Y. S. Sato ${ }^{1}$, and H. Kokawa ${ }^{1,3}$ \\ ${ }^{1}$ Department of Materials Processing, Graduate School of Engineering, Tohoku University, \\ Sendai, 980-8579 Japan \\ ${ }^{2}$ Belgorod National Research University, Belgorod, 308015 Russia \\ ${ }^{3}$ Shanghai Key Laboratory of Materials Laser Processing and Modification, \\ School of Materials Science and Engineering, Shanghai Jiao Tong University, Shanghai, 200240 China \\ *e-mail:mironov@bsu.edu.ru
}

Received October 29, 2018, revised February 21, 2019, accepted February 21, 2019

\begin{abstract}
In this work, the current state of understanding of grain structure evolution during friction-stir welding is briefly reviewed. The broad aspects of this process and experimental techniques for its examination are critically addressed. The specific character of the microstructural evolutions in body-centered cubic, face-centered cubic and hexagonal close-packed metals are considered in details. In all cases, the grain structure evolution is shown to be a relatively complex process, which usually involves geometric effect of strain, continuous recrystallization and discontinuous recrystallization. Moreover, mechanical twinning, annealing twinning and grain convergence may also occur in particular cases. It is also demonstrated that activation of a specific microstructural mechanism is primarily governed by crystal structure and stacking fault energy but may also be influenced by welding temperature. Specifically, microstructure evolution in cubic metals with high stacking-fault energy is primarily governed by the continuous recrystallization whereas grain structure development in materials with low stacking-fault energy is mainly driven by the discontinuous recrystallization. In the case of transient stacking-fault energy, the materials may experience a transition from the continuous to the discontinuous mechanism. In hexagonal metals, microstructural changes are shown to be directly linked with crystallographic texture. Specifically, a formation of very sharp texture may promote the grain convergence.
\end{abstract}

DOI: $10.1134 / \mathrm{S} 1029959920010038$

Keywords: friction-stir welding, microstructure, texture, electron backscatter diffraction

\section{INTRODUCTION}

Friction-stir welding is an innovative technique which enables solid-state joining of materials [1-3]. The basic concept of this technology is shown in Fig. 1. Friction-stir welding requires a specially designed, nonconsumable welding tool, which typically consists of two principal sections: the larger upper shoulder and the smaller bottom probe. The rotating tool is plunged into the joint line between two butted sheets until the shoulder comes into intimate contact with the sheet surface. The induced frictional heating and plastic deformation rises the local temperature of the material so it can be readily deformed. Under this condition, the tool is traversed along the joint line. The hot material is forced to flow around the rotating probe to fill the cavity at the rear of the translating tool and thus forming a joint in a solid state.
The solid-state character of the welding process avoids solidification problems inherent to conventional fusion techniques and therefore results in defect-free welds with excellent service properties. Accordingly, friction-stir welding is currently well-proven to be highly efficient welding technology which has great industrial potential.

It should be noted that the friction-stir welded material undergoes very large strains at elevated temperature and high strain rate. This normally leads to drastic microstructural changes. It should be noted that material behavior under such extreme combination of deformation conditions is not studied well and therefore microstructural examinations of the friction-stir welded materials represent essential academic interest.

In this work, the current state of understanding of the microstructure evolution during friction-stir weld- 
ing is briefly reviewed. Considering the pronounced complexity of this process, the current analysis is limited by relatively simple cases. Specifically, the materials experiencing phase transformations (including dissolution and/or precipitation of second-phase particles) during friction-stir welding thermal cycle are excluded from consideration. Moreover, the effect of the secondary particles on the strain-induced processes was also omitted for simplicity.

It should be emphasized that the authors of this work attempted to overview the current state-of-art in understanding of grain-structure development during friction-stir welding rather than identify individual contributions to this issue. To this end, the following strategy has been employed: (i) the key ideas and/or results were extracted from analysis of the body of work on the subject, (ii) they were appropriately categorized, and (iii) their brief review has been provided.

\section{BROAD ASPECTS OF MICROSTRUCTURE EVOLUTION}

As mentioned above, friction-stir welding creates unique combination of deformation conditions. This promotes a very specific character of the resulting microstructural changes. The broad aspects of this process are briefly discussed in this section.

The heat input induced by the rotating tool results in material heating thus giving rise to a heat-affected zone (Fig. 2). Accordingly, the microstructure evolution begins from annealing phenomena. Depending on peak temperature as well as initial material, recovery

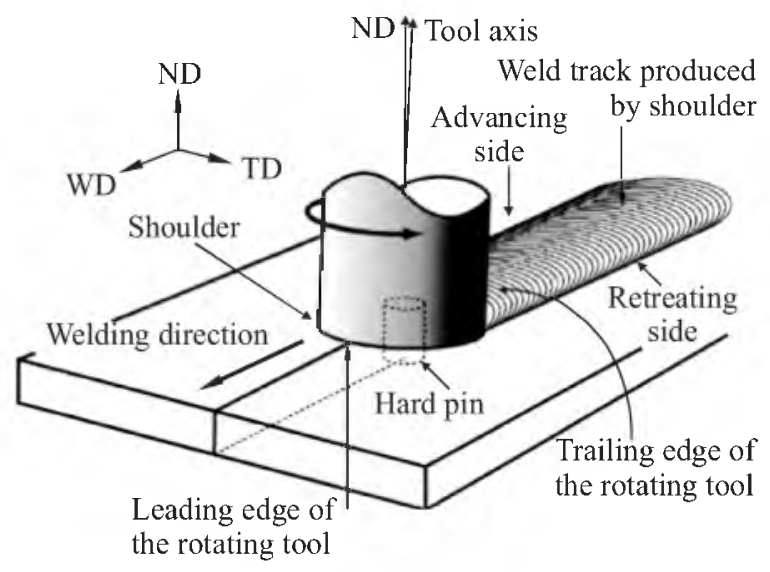

Fig. 1. Schematic illustration of friction-stir welding process (after Park et al. [4]). WD, ND and TD are welding direction, normal direction and transverse direction, respectively. and/or recrystallization may occur. Approaching the welding tool, the material undergoes plastic deformation, thereby forming a thermomechanically affected zone (Fig. 2). Remarkably, the temperature and strain increase rapidly across this region, and therefore a sharp microstructural gradient is expected. The material entrapped by the rotating tool experiences the largest strain at the highest temperature and finally produces a stir zone (Fig. 2). Taking into account the characteristic mushroom-shaped design of the welding tool, the material in the upper section of the stir zone may experience a secondary deformation induced by the rotating shoulder. Moreover, considering the hightemperature character of the deformation process, the welded material may undergo additional microstructural changes after friction-stir welding, during cooling down to ambient temperature.

\section{EXPERIMENTAL TECHNIQUES FOR EXAMINATION OF MICROSTRUCTURAL EVOLUTION}

Considering a very specific character of frictionstir welding process, the experimental investigation of underlying microstructural evolution is challenging. At present, two approaches are typically used and those are briefly discussed in this section.

The first method is based on microstructural examinations of the thermomechanically affected zone (Fig. 2). In this region, initial microstructure gradually transforms from the base material structure into the final stir zone microstructure. Thus, a transient nature of this microstructural zone is believed to be a key issue to ascertain microstructure evolution during friction-stir welding. This approach is very simple and thus it is often applied in practice. However, considering multistage character of the friction-stir welding process, the accuracy of this method is relatively low and some important details of the microstructural changes may be missed.

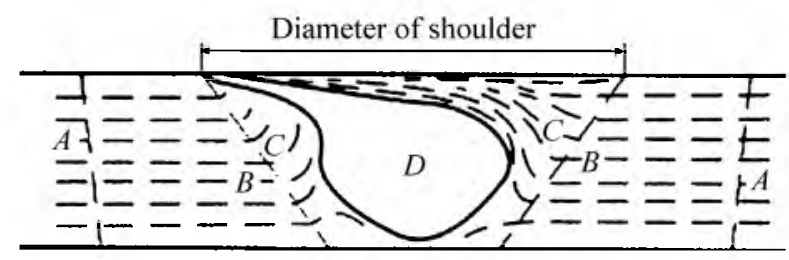

Fig. 2. Schematic cross-section of a typical friction-stir welding weld showing four characteristic zones: base material $(A)$, heat-affected zone $(B)$, thermo-mechanically affected zone $(C)$, and stir zone $(D)$ (after Nandan et al. [3]). 
The second method is the so-called "stop-action" technique [5]. It involves emergency stoppage of the welding machine during friction-stir welding and immediate quenching of the welded material to "freeze" the deformation-induced microstructure evolved near the welding tool. In some cases, a rapid tool extraction is used instead of its stoppage [6-8]. To enhance the quenching effect, a liquid $\mathrm{CO}_{2}$ is recommended to use [9-12]. The stop-action approach is believed to allow a direct observation of the deformation-induced microstructures and therefore it is widely recognized to be the most effective method for examination of the microstructural evolution. It should be emphasized, however, that the rotating tool cannot be stopped instantly due to the inertia in the friction-stir welding system. Specifically, mechanical relaxation of the system results in shifting of the welding tool from the position of the actual weld termination $[13,14]$. As a result, the tool stoppage (or tool extraction) effect should inevitably influence the material adjacent the welding tool. Therefore, this technique is only applicable at relatively low rotational and travel speeds and caution is necessary for interpretation of the experimental results.

\section{BODY-CENTERED CUBIC METALS}

In body-centered cubic (bcc) metals, grain structure evolution during friction-stir welding is relatively poorly understood. So far, this process has been inves- tigated only in pure iron [15] and $\beta$-titanium [16-18], to the best of the authors' knowledge.

In pure iron, microstructural changes have been reported to initiate from a development of extended lowangle boundaries in interior of parent grains, as shown in Figs. 3a and 3b. Remarkably, the low-angle boundaries are typically arranged as regular arrays of nearly parallel bands aligned in common direction within grains. This subdivides the original grains into clearly defined fragments. With increasing in strain, the lowangle boundaries rapidly accumulate misorientation thus gradually transforming into deformation-induced high-angle boundaries, as exemplified by arrows in Fig. 3c. This results in significant grain orientation spread, and therefore the parent grains become poorly recognizable. In the proximity of the stir zone, the original grains are significantly drawing out due to geometrical requirements of strain imposed by the rotating tool, thus becoming thin fibrous grains (Fig. 3a). Simultaneously, the development of the deformationinduced boundaries breaks up the initial grain structure and produces a fine-grained lamella structure, which consists of high-angle boundaries aligned in a common direction cross linked by low-angle boundaries (Fig. 3d).

Generally, the microstructure evolution was found to be broadly similar to the grain subdivision process, which is often observed during large plastic deformation of cubic metals of medium to high stacking fault energy [19-21]. In this process, plastic deformation
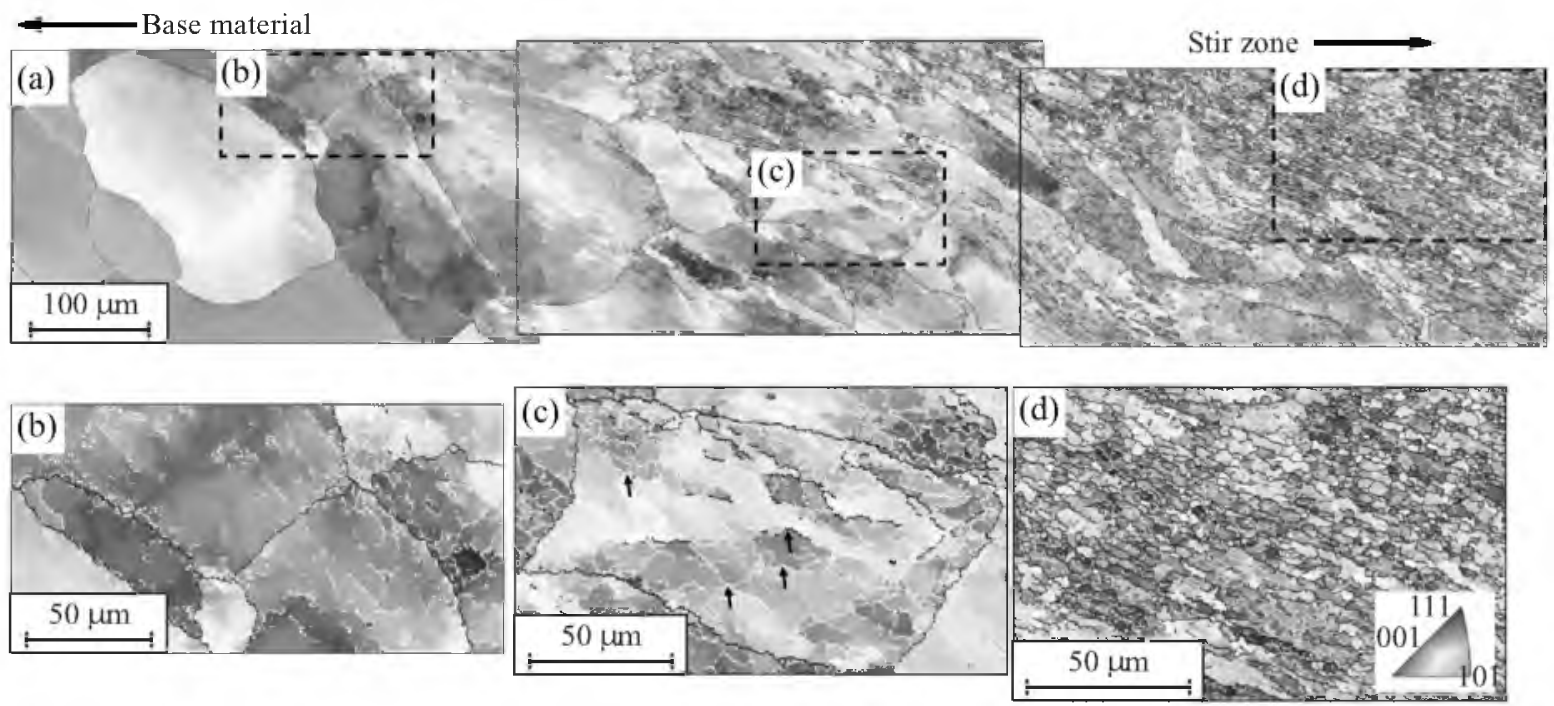

Fig. 3. Microstructure evolution during friction-stir welding of pure iron (after Mironov et al. [15]) electron backscatter diffraction (EBSD): (a) composite EBSD map taken from thermomechanically affected zone with selected areas shown at higher magnifications in (b) through (d). In the map, individual grains are colored according to their crystallographic orientation, and low- and highangle boundaries are depicted as white and black lines, respectively. See Sect. 4 for details.

PHYSICAL MESOMECHANICS Vol. 23 No. 12020 
also results in subdivision of initial grains into lamellar-shaped fragments. Due to limited number of neighbors in such microstructure, the strain compatibility constraints are partially relaxed and thus the number of operating slip systems within each fragment is fever than that required by the Taylor model. This provides energy benefits. On the other hand, the Taylor condition is fulfilled by all fragments collectively, at a grain scale. Accordingly, different slip systems operate within each fragment thus promoting their crystallographic rotations in diverging directions. As a result, deformation-induced boundaries develop between the fragments, and misorientations of such boundaries continuously increase with strain. This finally transforms the fragment boundaries into high-angle boundaries thus giving rise to microstructural refinement.

In $\beta$ titanium, microstructural examinations showed contradictive results. In some cases, the grain structure development has been also interpreted in terms of the grain subdivision mechanism [16], whereas other works have attributed this process to discontinuous recrystallization [18].

\section{FACE-CENTERED CUBIC METALS}

It is well accepted that microstructural behavior of face-centered cubic (fcc) metals essentially depends on stacking fault energy. Accordingly, these materials are categorized into three broad groups, i.e. high stacking fault energy metals $\left(\geq 100 \mathrm{~mJ} \mathrm{~m}^{-2}\right)$, low stacking fault energy metals $\left(\leq 25 \mathrm{~mJ} \mathrm{~m}^{-2}\right)$ and transient metals.

\subsection{High Stacking Fault Energy}

The grain structure development during frictionstir welding of face-centered metals with high stacking fault energy has been best investigated in aluminum alloys. It has been conclusively demonstrated that the microstructure evolution of such materials is relatively complex process, which is significantly influenced by welding temperature and cooling rate.

At relatively low temperatures $\left(\sim 0.5 T_{\mathrm{m}}\right.$, where $T_{\mathrm{m}}$ is the melting point), the grain structure development has been reported to be driven by the grain subdivision mechanism [22], similar to that discussed in the previous section. A representative example is shown in Fig. 4. The activation of the grain subdivision re-
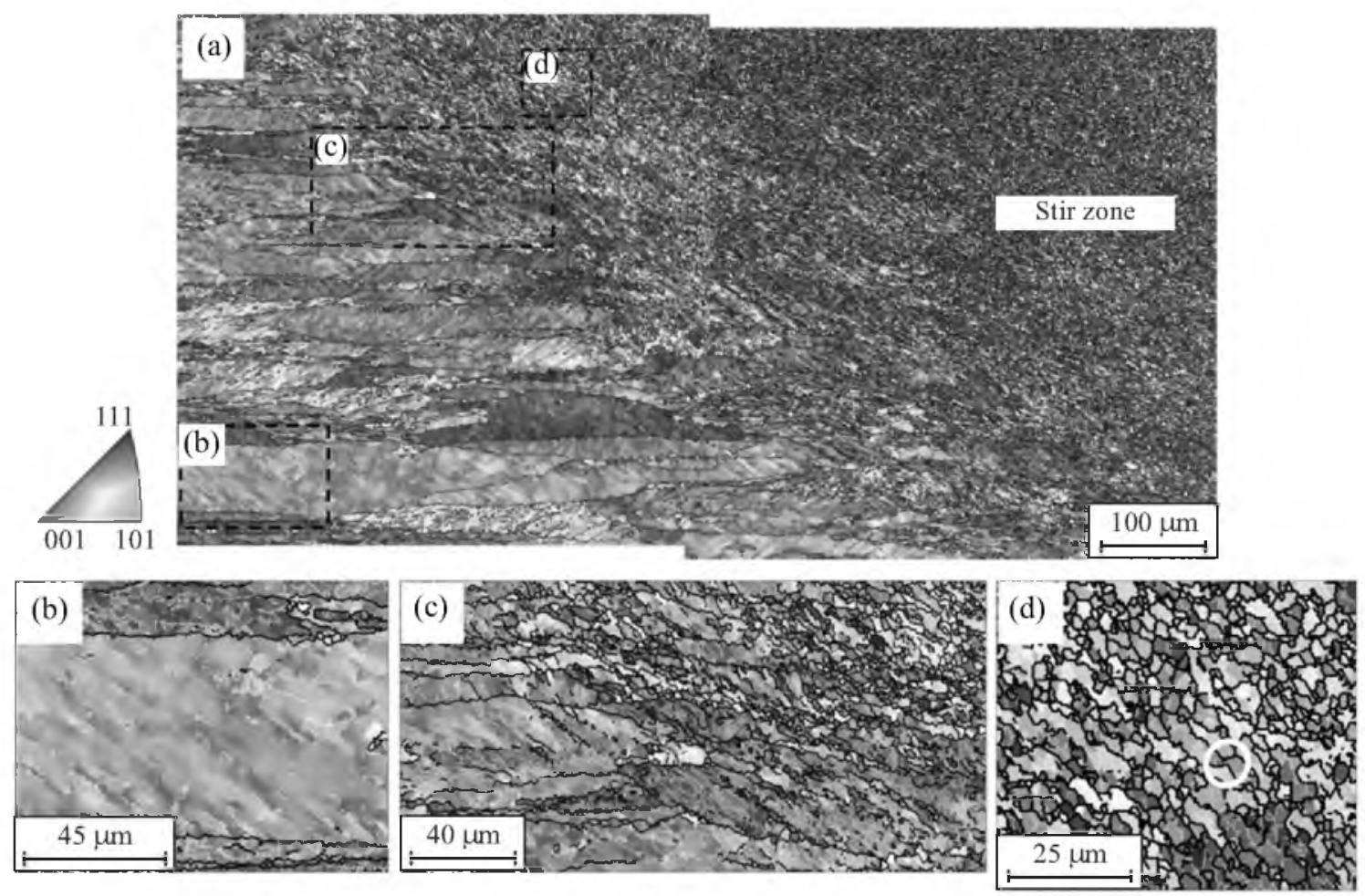

Fig. 4. Microstructure evolution during low-temperature friction-stir welding of 1050 aluminum alloy (after Mironov et al. [22]): (a) composite EBSD map taken from thermomechanically affected zone with selected areas shown at higher magnifications in (b) through (d). In the map, individual grains are colored according to their crystallographic orientation, and low- and high-angle boundaries are depicted as white and black lines, respectively. See Sect. 5.1 for details. 

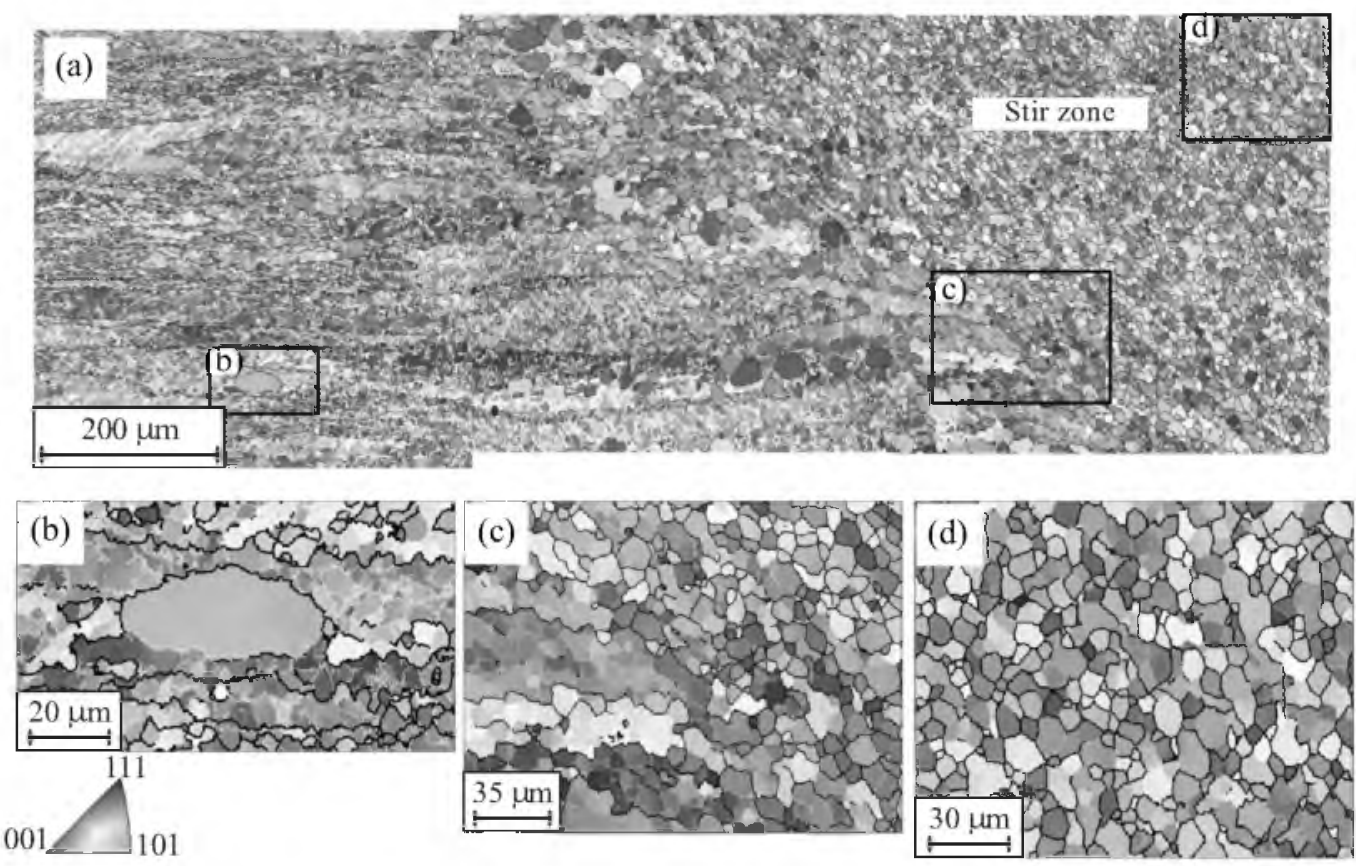

Fig. 5. Microstructure evolution during high-temperature friction-stir welding of 1050 aluminum alloy (after Mironov et al. [22]): (a) composite EBSD map taken from thermomechanically affected zone with selected areas shown at higher magnifications in (b) through (d). In the map, individual grains are colored according to their crystallographic orientation, and low- and high-angle boundaries are depicted as white and black lines, respectively. See Sect. 5.1 for details.

sults in the formation of deformation-induced lamella structure (Fig. 4d). The lamellar morphology of the evolved structure provides partial relaxation of strain compatibility requirements thus giving rise to a development of $C\{001\}\langle 110\rangle$ texture component [22].

An increase of the welding temperature enhances grain-boundary mobility thus resulting in local grainboundary migration. This complicates microstructural evolution. Though this process is still governed by the development of deformation-induced boundaries and the subsequent low-angle boundary to high-angle boundary transformation, it cannot be longer explained in relative simple terms of the grain subdivision model. Instead, the grain structure development in such cases is often categorized in broader terms of continuous recrystallization $[9,22-25]$.

Considering the formation of the fine-grained lamella structure (Fig. 4d), the local grain boundary bulging may also result in geometrical recrystallization [26]. In this process, original grain boundaries impinge each other thus subdividing elongated parent grains into shorter low-aspect ratio fragments. An example of this process is circled in Fig. $4 \mathrm{~d}$.

At relatively high welding temperatures, the local grain-boundary migration may also give rise to local recrystallization nuclei thus indicating a development of limited discontinuous recrystallization [22], as exemplified in Figs. 5a and 5b. However, the contribution of this process is relatively small and the continuous recrystallization is often believed to be the dominant microstructural mechanism $[9,22-25]$. This is in the line with widely accepted conception of microstructural behavior of high stacking fault energy metals. Due to relatively high dislocation mobility in such materials, the dislocations may rapidly rearrange into dislocation boundaries thus promoting a development of the continuous recrystallization. On the other hand, this reduces density of free dislocations and therefore decreases a driving force for the discontinuous recrystallization.

It should be noted, however, that microstructural evolution during friction-stir welding of $7 \mathrm{xxx}$ aluminum alloys is often reported to be driven by the discontinuous mechanism $[6,7,27]$. The reason for the exceptional behavior of these alloys is not clear.

The increase of the grain-boundary mobility with temperature fundamentally alters the morphology of the strain-induced microstructure from a lamellar type to an equiaxed type (Figs. 5c and $5 \mathrm{~d}$ ). This changes the strain compatibility requirements at grain boundaries and thus leads to a principal change of the crystallographic texture from $C\{001\}\langle 110\rangle$ to $B / \bar{B}\{112\}\langle 110\rangle$ 
[22]. Moreover, the increase of the welding temperature reduces dislocation density and therefore slows down the continuous recrystallization. The incompleteness of this process at relatively high temperatures may result in relatively low high-angle boundary fraction [22].

It is also worth noting that the materials welded at relatively high temperatures may experience significant microstructural changes during weld cooling cycle $[9,26,28,29]$. Specifically, this may induce substantial grain coarsening which, in turn, may result in essential changes in texture [28] as well as in misorientation distribution [29].

\subsection{Low Stacking Fault Energy}

Microstructure evolution during friction-stir welding of low stacking fault energy materials has been studied in austenitic stainless steels [13-14, 30-34] and $\mathrm{Cu}-30 \mathrm{Zn}$ brass [35-37]. It should be emphasized that all these materials are relatively difficult for welding and thus the friction-stir welding processing window is relatively narrow. Accordingly, the effect of friction-stir welding variables on grain structure development is relatively hard to study.

The low stacking fault energy materials are usually supplied in well-annealed condition and thereby the base material is typically characterized by relatively coarse-grained structure which contains significant fraction of annealing twins. The constituent secondphase particles (if present) are normally stable at friction-stir welding temperatures. Accordingly, the friction-stir welded low stacking fault energy materials normally exhibit no clear heat-affected zone.

A typical pattern of microstructure evolution is illustrated in Fig. 6. The beginning stage of process is typically characterized by a gradual transformation of original annealing twin boundaries into random (nontwin) boundaries $[30,35]$. An example of the transformed twin boundary is arrowed in Fig. 6b. This effect is well known being usually ascribed to straininduced crystallographic rotations of the twins and the surrounding matrix, which destroys the ideal twinmatrix orientation relationship [38].

An increase in strain promotes low-angle boundary formation. In contrast to high stacking fault energy metals, however, this process preferentially develops near original grain boundaries, and the evolved low-angle boundaries are relatively poorly developed (Fig. 6c) [30, 35].

At relatively low welding temperatures, the microstructure evolution may additionally be characterized by extensive mechanical twinning [35]. In contrast to

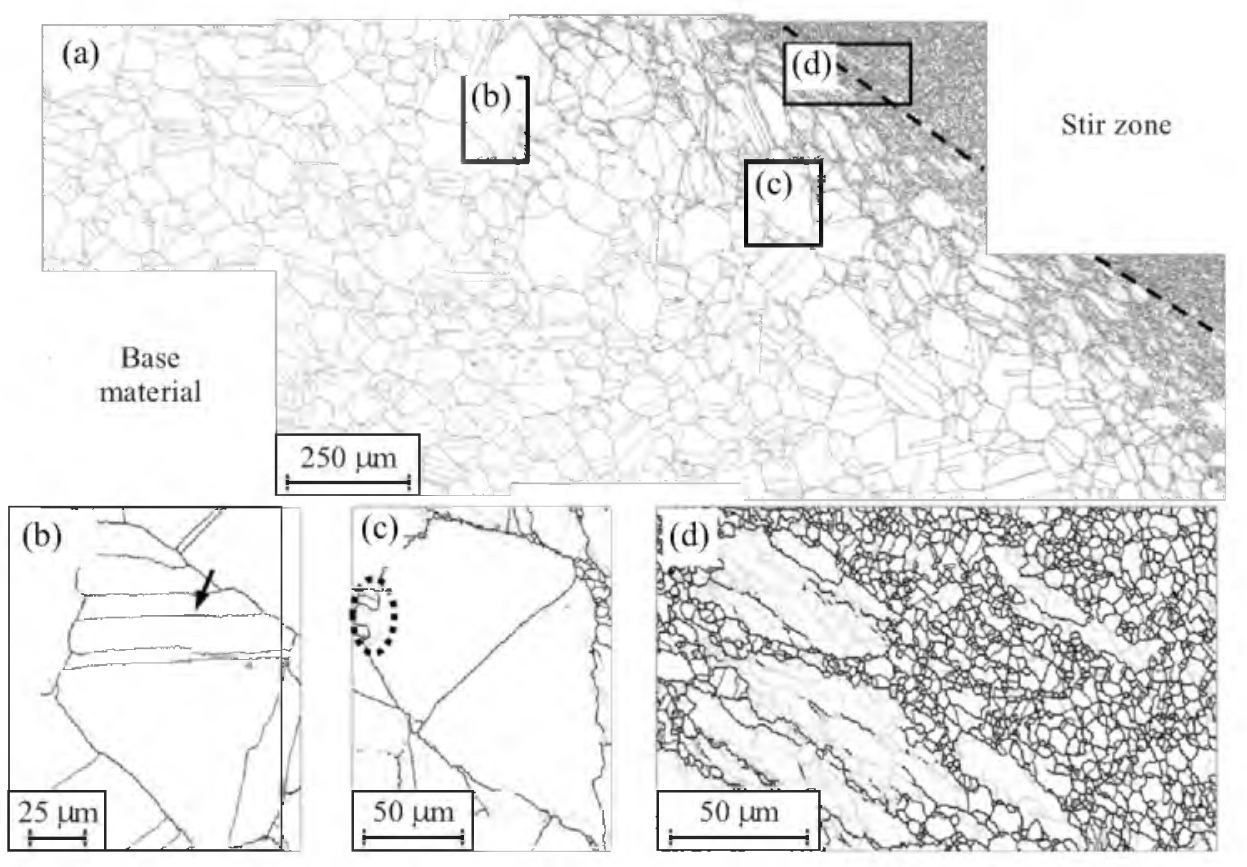

Fig. 6. Microstructure evolution during friction-stir welding of superaustenitic stainless steel (after Mironov et al. [30]): (a) composite EBSD map taken from thermomechanically affected zone with selected areas shown at higher magnifications in (b) through (d). In the map, low-angle boundaries, high-angle boundaries, and $\Sigma 3$ twin boundaries are depicted as gray, black and solid gray lines, respectively. See Sect. 5.2 for details. 
annealing twinning, the mechanical twins typically have lenticular or wedge-shaped morphology, are relatively thin and tend to group in series [35].

The further increase in strain and temperature approaching to the stir zone gives rise to grain boundary bulging [30-32, 35, 37]. A typical example is circled in Fig. $6 \mathrm{c}$. The bulges subsequently transform into recrystallization nuclei thus evidencing an activation of the discontinuous recrystallization [14, 30-35]. This observation agrees well with commonly accepted conception of structural behavior of low stacking fault energy materials during hot deformation. The relatively low dislocation mobility in such alloys prevents their rapid rearrangement in dislocation boundaries and thus suppresses the continuous recrystallization; on the other hand, the resulting high dislocation density creates the driving force for the discontinuous recrystallization.

During friction-stir welding, the development of the discontinuous recrystallization results in bimodal grain structure, which consists of coarse remnants of original grains surrounded by a necklace of fine-recrystallized grains [30, 35], as exemplified in Fig. 6d. The local grain-boundary migration also promotes annealing twinning and the recrystallized grains normally contain annealing twins [14, 30-35] (Fig. 6d).

On the other hand, the survived coarse-grained remnants of the original structure often exhibit regular arrays of deformation-induced boundaries $[30,35]$, as shown in Fig. 6d. These boundaries are reasonably straight and extend across entire grains thus subdividing them into relatively coarse fragments. The misorientation across such boundaries often exceeds $15^{\circ}$ thus transforming them into high-angle boundaries. In other words, the observed process is closely reminiscent of the grain subdivision, as discussed in Sect. 4. Therefore, the microstructure evolution during frictionstir welding of the low stacking fault energy materials is usually a competition between the discontinuous recrystallization and the continuous recrystallization $[30-35,37]$.

With further increase in strain, the recrystallized grains gradually consume the coarse grained remnants, thus forming the nearly-fully recrystallized stir zone microstructure [14, 30-35], as shown in Fig. 6d. This perhaps evidences that the discontinuous recrystallization is the dominant microstructural mechanism. Remarkably, the annealing twin boundaries in the final grain structure are typically very close to the ideal twin/matrix orientation relationship [30], i.e. they experienced almost no strain. Considering a relatively low thermal conductivity of the low stacking fault energy materials (which assumes a relatively low cooling rate), this may indicate that significant portion of the discontinuous recrystallization occurs after friction-stir welding, during weld cooling cycle. The pronounced post-weld annealing effect has been directly demonstrated by the stop-action experiments $[14,36]$.

It should be noted, however, that microstructural evolution at very low temperatures (e.g. during tool plunging step) may be governed by the subdivision mechanism, as shown by Jeon et al. [31, 32].

The textural patterns in the stir zone are often interpreted in terms of the superposition of either partial $\langle 110\rangle$ and $\{111\}$ fibers or $A / \bar{A}\{111\}\langle 110\rangle$ simple shear textures $[30-32,34,35]$. Sometimes, this observation is attributed to suppression of cross-slip due to low stacking fault energy [30]. On the other hand, it has been also associated with nearly-equaixed morphology of the microstructure produced during the discontinuous recrystallization [35], as evident from Fig. 6d. Such microstructure morphology assumes very strict strain compatibility requirements which may promote the formation of the $A / \bar{A}$ texture [39].

\subsection{Moderate Stacking Fault Energy}

The grain structure development during frictionstir welding of face-centered metals with moderate stacking fault energy has been investigated in commercial purity copper.

The microstructure evolution in this material was found to principally depend on the welding temperature. At the temperatures below $\sim 0.5 T_{\mathrm{m}}$, grain structure development has been reported to be primarily governed by the continuous recrystallization [40]. This resulted in a formation of relatively fine grained $(\sim 1-$ $2 \mu \mathrm{m})$ microstructure in the stir zone [40]; in some cases, even a development of ultrafine-grained structure was observed [7]. The evolved texture was dominated by $A / \bar{A}\{111\}\langle 110\rangle$ simple shear orientations [40].

At the temperatures above $\sim 0.5 T_{\mathrm{m}}$, the microstructural evolution was dominated by the discontinuous recrystallization [40]. This produced a relatively coarse $(\sim 10-30 \mu \mathrm{m})$ microstructure and $\{111\}\langle u v w\rangle$ fiber texture in the stir zone [40]. The application of the stop-action technique demonstrated that the discontinuous recrystallization occurred primarily during weld cooling cycle $[7,11,12,40]$. 
(a)
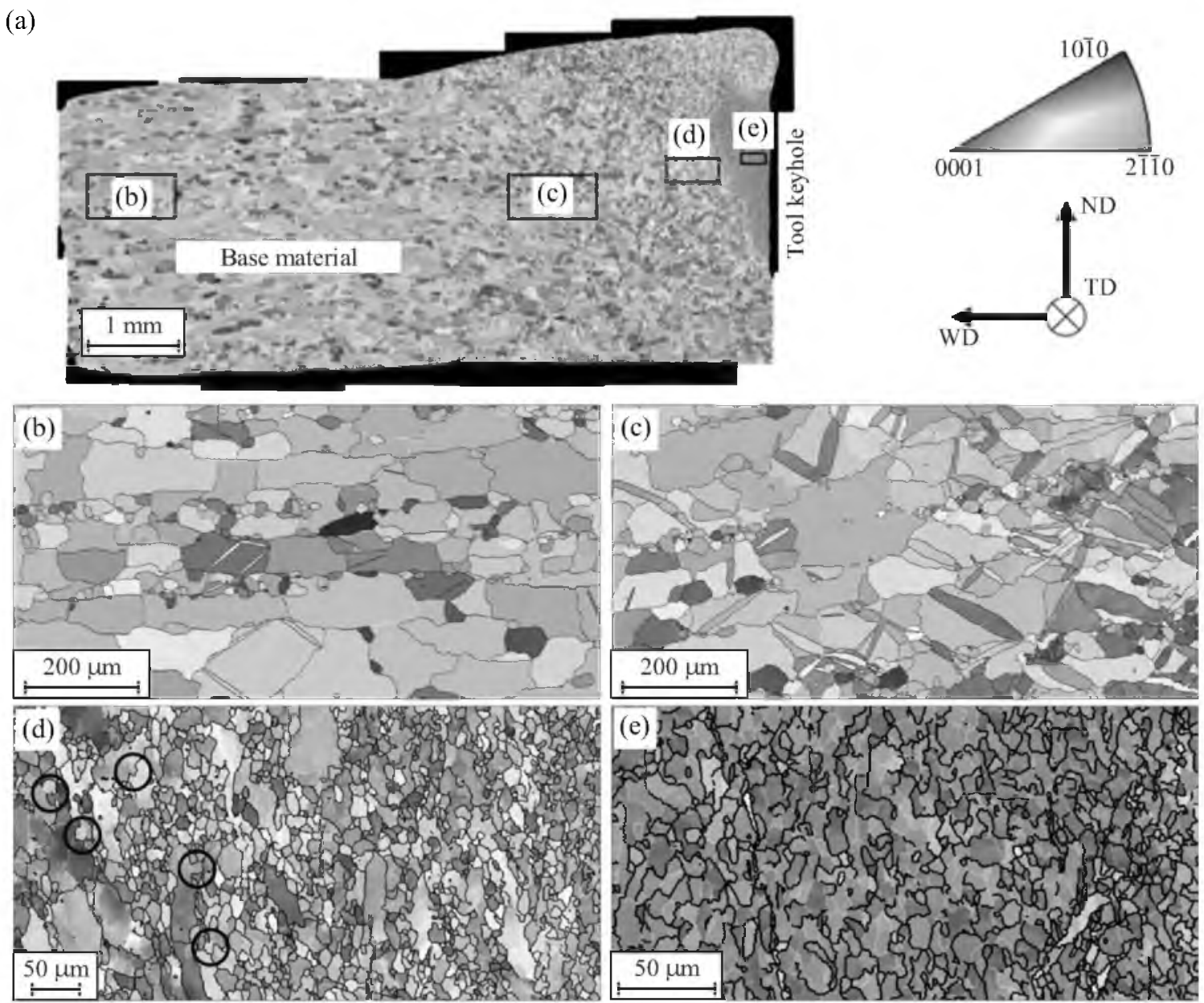

Fig. 7. Microstructure evolution during friction-stir welding of AZ31 magnesium alloy (after Mironov et al. [41]): (a) composite EBSD map taken from the deformation zone evolved ahead of the welding tool during stop-action experiment with selected areas shown at higher magnifications in (b) through (e). In the map, individual grains are colored according to their crystallographic orientation, and low- and high-angle boundaries are depicted as white and black lines, respectively. See Sect. 6 for details.

\section{HEXAGONAL CLOSE-PACKED METALS}

Microstructure evolution during friction-stir welding of hexagonal close-packed (hcp) metals has been studied in magnesium alloys [41-47], commercial purity titanium [48], and commercial purity zirconium [49].

The grain structure development in these materials has been reported to be a complex process which involved several stages, as exemplified in Fig. 7. At relatively cold periphery of a deformation zone ahead the welding tool, mechanical twinning may occur [41-43] (Figs. 7a and 7c). In the case of magnesium alloys, $\{10 \overline{1} 2\}$ twinning is typically reported to predominate [41-43]. Since the twinning is sensitive to grain size as well as crystallographic texture, the microstructure evolution may be essentially influenced by initial material condition [44].
Approaching to the stir zone, the original grains and the twins are geometrically reoriented in a flow pattern around the welding tool due to the geometrical requirements of imposed strain [41, 42, 46, 48], as shown in Fig. $7 \mathrm{~d}$. The twin boundaries transform into random high-angle boundaries [41], similar to that discussed in Sect. 5.2. The temperature increase promotes grain-boundary bulging along original grain boundaries $[41,42,46,48]$; several examples of this process are circled in Fig. 7c. The progressive development of this process gives rise to the necklace structure, thus indicating an activation of the discontinuous recrystallization [41-43, 46-48] (Fig. 7c).

At close proximity to the stir zone, a very strong crystallographic texture develops (20-50 times random) $[41-43,45,46,48]$. In magnesium alloys, $B$-fiber $\{0001\}\langle u v t w\rangle$ texture predominates $[41-43,45,46]$, 
whereas $P$-fiber $\{h k i l\}\langle 11 \overline{20}\rangle$ texture evolves in titanium [48]. The formation of the very strong texture may impose strict limitations on misorientations of grain boundaries. Specifically, the development of the sharp $B$-fiber texture restricts the maximal allowable misorientation by $30^{\circ}[42,45,46]$. As a result, an extensive lowering of grain-boundary misorientations may occur [41]. This unusual effect is termed grain convergence [41, 42, 45, 48].

The formation of the final stir zone microstructure has been reported to be driven by continuous recrystallization $[41,43,46,47]$ and the grain convergence $[41,42,45,48]$. A typical example of the stir zone microstructure is given in Fig. 7e.

An increase of the welding temperature reduces mechanical twinning but increases the contribution of the discontinuous recrystallization in the microstructure evolution [41].

During friction-stir welding cooling cycle, the welded material may experience static grain coarsening, which may affect mean grain size, texture strength and misorientation distribution [41, 45].

\section{SUMMARY}

In this work, the current understanding of grain structure evolution during friction-stir welding was briefly reviewed. The main conclusions are as follows.

The grain structure development during frictionstir welding is relatively complex process, which usually involves geometrical effect of strain, continuous recrystallization and discontinuous recrystallization. Moreover, mechanical twinning, annealing twinning and grain convergence may also occur in particular cases. The activation of particular microstructural mechanism is primarily governed by crystal structure as well as stacking fault energy of material but may also be influenced by welding temperature.

Specifically, microstructure evolution during friction-stir welding of cubic metals with high stacking fault energy is primarily governed by continuous recrystallization. On the other hand, microstructural behavior of cubic metals with low stacking fault energy in mainly driven by discontinuous recrystallization. The materials with transient stacking fault energy may experience a transient from continuous recrystallization to discontinuous recrystallization with increasing of the welding temperature. The grain structure evolution of hexagonal metals is closely linked with a development of crystallographic texture. Specifically, the formation of a very sharp texture in stir zone may promote grain convergence.

During friction-stir welding cooling cycle, the welded material may experience substantial grain coarsening or even static recrystallization. This may essentially influence the final microstructure and texture in the stir zone.

\section{FUNDING}

One of the coauthors (S. Mironov) would like to acknowledge the financial support from the Russian Science Foundation, grant No. 19-49-02001.

\section{REFERENCES}

1. Thomas, W.M., Int. Patent No. PCT/GB92/02203. Friction Stir Butt Welding, 1991.

2. Mishra, R.S. and Ma, Z.Y., Friction Stir Welding and Processing, Mater Sci. Eng. R, 2005, vol. 50, pp. 1-78. doi 10.1016/j.mser.2005.07.001

3. Nandan, R., DebRoy, T., and Bhadeshia, H.K.D.H., Recent Advances in Friction-Stir Welding - Process, Weldment Structure and Properties, Progr Mater. Sci., 2008, vol. 53, pp. 980-1023. doi 10.1016j.pmatsci.2008. 05.001

4. Park, S.H.C., Sato, Y.S., and Kokawa, H., Basal Plane Texture and Flow Pattern in Friction Stir Weld of a Magnesium Alloy, Metall. Mater. Trans. A, 2003, vol. 34, pp. 987-994. doi 10.1007/s11661-003-0228-4

5. Colligan, K., Material Flow Behavior during Friction Stir Welding, Weld. J., 1999, vol. 78, no. 7, pp. 229 237.

6. Rhodes, C.G., Mahoney, M.W., Bingel, W.H., and Calabrese, M., Fine-Grain Evolution in Friction-Stir Processed 7050 Aluminum, Scripta Mater, 2003, vol. 48, pp. 14511455. doi 10.1016/S1359-6462(03)00082-4

7. Su, J.-Q., Nelson, T.W., and Sterling, C.J., Microstructure Evolution during FSW/FSP of High Strength Aluminum Alloys, Mater. Sci. Eng. A, 2005, vol. 405, pp. 277-286. doi 10.1016/j.msea.2005.06.009

8. Su, J.-Q., Nelson, T.W., McNelley, T.R., and Mishra, R.S., Development of Nanocrystalline Structure in $\mathrm{Cu}$ during Friction Stir Processing (FSP), Mater. Sci. Eng. A, 2011, vol. 528, pp. 5458-5464. doi 10.1016/ j.msea.2011.03.043

9. Liu, X.C., Sun, Y.F., and Fujii, H., Clarification of Microstructure Evolution of Aluminum during Friction Stir Welding Using Liquid $\mathrm{CO}_{2}$ Rapid Cooling, Mater. Design, 2017, vol. 129, pp. 151-163. doi 10.1016j.matdes. 2017.05.013

10. Xu, N., Ueji, R., and Fujii, H., Enhanced Mechanical Properties of 70/30 Brass Joint by Rapid Cooling Fric- 
tion Stir Welding, Mater. Sci. Eng. A, 2014, vol. 610, pp. 132-138. doi 10.1016/j.msea.2014.05.037

11. Xu, N., Ueji, R., and Fujii, H., Dynamic and Static Change of Grain Size and Texture of Copper during Friction Stir Welding, J. Mater Proc. Technol, 2016 , vol. 232, pp. 90-99. doi 10.1016/j.jmatprotec.2016.01. 021

12. Xu, N., Ueji, R., Morisada, Y., and Fujii, H., Modification of Mechanical Properties of Friction Stir Welded $\mathrm{Cu}$ Joint by Additional Liquid $\mathrm{CO}_{2}$ Cooling, Mater: Design, 2014, vol. 56, pp. 20-25. doi 10.1016j.matdes. 2013.10.076

13. Liu, F.C. and Nelson, T.W., In-Situ Material Flow Pattern Around Probe during Friction Stir Welding of Austenitic Stainless Steel, Mater. Design, 2016, vol. 110, pp. 354-364. doi 10.1016/j.matdes.2016.07.147

14. Liu, F.C. and Nelson, T.W., In-Situ Grain Structure and Texture Evolution during Friction Stir Welding of Austenite Stainless Steel, Mater: Design, 2017, vol. 115, pp. 467-478. doi 10.1016/j.matdes.2016.11.066

15. Mironov, S., Sato, Y.S., and Kokawa, H., Microstructural Evolution during Friction Stir-Processing of Pure Iron, Acta Mater, 2008, vol. 56, pp. 2602-2614. doi 10.1016/j.actamat.2008.01.040

16. Mironov, S., Zhang, Y., Sato, Y.S., and Kokawa, H., Development of Grain Structure in $\beta$-Phase Field during Friction Stir Welding of Ti-6Al-4V Alloy, Scripta $M a-$ ter, 2008, vol. 59, pp. 27-30. doi 10.1016j.scriptamat. 2008.02.014

17. Pilchak, A.L., Tang, W., Sahiner, H., Reynolds, A.P., and Williams, J.C., Microstructure Evolution during Friction Stir Welding of Mill-Annealed Ti-6Al-4V, Metall. Mater: Trans. A, 2011, vol. 42, pp. 745-762.

18. Mironov, S., Sato, Y.S., and Kokawa, H., Microstructural Evolution during Friction Stir Welding of Ti-15V3Cr-3Al-3Sn Alloy, Mater Sci. Eng. A, 2010, vol. 527, pp. 7498-7504. doi 10.1016/j.msea.2010.08.074

19. Bay, B., Hansen, M., Hughes, D.A., and KuhlmannWilsdorf, D., Evolution of FCC Deformation Structures in Polyslip, Acta Metall. Mater, 1992, vol. 40, pp. 205219. doi 10.1016/0956-7151(92)90296-Q

20. Hughes, D.A. and Hansen, N., High Angle Boundaries Formed by Grain Subdivision Mechanisms, Acta Mater, 1997, vol. 45, pp. 3871-3886. doi 10.1016/S13596454 (97)00027-X

21. Hansen, N. and Jensen, D.J., Development of Microstructure in Face-Centered Cubic Metals during Cold Work, Philos. Trans. R. Soc. Lond. A, 1999, vol. 357, pp. 1447-1469. doi 10.1098/rsta.1999.0384

22. Mironov, S., Inagaki, K., Sato, Y.S., and Kokawa, H., Effect of Welding Temperature on Microstructure of Friction-Stir Welded Aluminum Alloy 1050, Metall. Mater: Trans. A, 2015, vol. 46, pp. 783-790. doi 10.1007/ s11661-014-2651-0
23. Fonda, R.W., Bingert, J.F., and Colligan, K.J., Development of Grain Structure during Friction Stir Welding, Scripta Mater, 2004, vol. 51, pp. 243-248. doi 10.1016/ j.scriptamat.2004.04.017

24. Jata, K.V. and Semiatin, S.L., Continuous Dynamic Recrystallization during Friction Stir Welding of High Strength Aluminum Alloys, Scripta Mater, 2000, vol. 43, pp. 743-749. doi 10.1016/S1359-6462(00)00480-2

25. Fonda, R.W. and Bingert, J.F., Precipitation and Grain Refinement in a 2195 Al Friction Stir Weld, Metall. Mater. Trans. A, 2006, vol. 37, pp. 3593-3604. doi 10.1007/s11661-006-1054-2

26. Prangnell, P.B. and Heason, C.P., Grain Structure Formation during Friction Stir Welding Observed by the "Stop Action Technique", Acta Mater, 2005, vol. 53, pp. 3179-3192. doi 10.1016/j.actamat.2005.03.044

27. Su, J.-Q., Nelson, T.W., and Sterling, C.J., Grain Refinement of Aluminum Alloys by Friction Stir Processing, Philos. Mag., 2006, vol. 86, pp. 1-24. doi 10.1080/ 14786430500267745

28. Suhuddin, U.F.H.R., Mironov, S., Sato, Y.S., and Kokawa, H., Grain Structure and Texture Evolution during Friction Stir Welding of Thin 6016 Aluminum Alloy Sheets, Mater. Sci. Eng. A, 2010, vol. 527, pp. 19621969. doi 10.1016/j.msea.2009.11.029

29. Yi, D., Mironov, S., Sato, Y.S., and Kokawa, H., Effect of Cooling Rate on Microstructure of Friction Stir Welded AA1100 Aluminum Alloy, Philos. Mag., 2016, vol. 96, pp. 1965-1977. doi 10.1080/14786435.2016.1185186

30. Mironov, S., Sato, Y.S., Kokawa, H., Inoue, H., and Tsuge, S., Structural Response of Superaustenitic Stainless Steel to Friction Stir Welding, Acta Mater, 2011, vol. 59, pp. 5472-5481. doi 10.1016/j.actamat. 2011. 05.021

31. Jeon, J., Mironov, S., Sato, Y.S., Kokawa, H., Park, S.H.C., and Hirano, S., Friction Stir Spot Welding of Single-Crystal Austenitic Stainless Steel, Acta Mater., 2011, vol. 59, pp. 7439-7449. doi 10.1016/j.actamat.2011.09.013

32. Jeon, J., Mironov, S., Sato, Y.S., Kokawa, H., Park, S.H.C., and Hirano, S., Grain Structure Development during Friction Stir Welding of Single-Crystal Austenitic Stainless Steel, Metall. Mat. Trans A, 2013, vol. 44, pp. 31573166, doi 10.1007/s11661-013-1692-0

33. Cui, H.B., Xie, G.M., Luo, Z.A., Ma, J., Wang, G.D., and Mishra, R.D.K., Microstructural Evolution and Mechanical Properties of the Stir Zone in Friction Stir Processed AISI201 Stainless Steel, Mater: Design, 2016, vol. 106, pp. 463-475. doi 10.1016/j.matdes.2016.05.106

34. Hajian, M., Abdollah-zadeh, A., Rezaei-Nejad, S.S., Assadi, H., Hadavi, S.M.M., Chung, K., and Shokouhimehr, M., Microstructure and Mechanical Properties of Friction Stir Processed AISI 316L Stainless Steel, Mater: Design, 2015, vol. 67, pp. 82-94. doi 10.1016j. matdes.2014.10.082 
35. Mironov, S., Inagaki, K., Sato, Y.S., and Kokawa, H., Development of Grain Structure during Friction-Stir Welding of $\mathrm{Cu}-30 \mathrm{Zn}$ Brass, Philos. Mag., 2014, vol. 94, pp. 3137-3147. doi 10.1080/14786435.2014.951712

36. Xu, N., Ueji, R., and Fujii, H., Enhanced Mechanical Properties of 70/30 Brass Joint by Rapid Cooling Friction Stir Welding, Mater. Sci. Eng. A, 2014, vol. 610, pp. 132-138. doi 10.1016/j.msea.2014.05.037

37. Heidarzadeh, A., Saeid, T, and Klemm, V., Microstructure, Texture, and Mechanical Properties of Friction Stir Welded Commercial Brass Alloy, Mater Character, 2016, vol. 119, pp. 84-91. doi 10.1016j.matchar.2016. 07.009

38. Salishchev, G., Mironov, S., Zherebtsov, S., and Belyakov, A., Changes in Misorientations of Grain Boundaries in Titanium during Deformation, Mater: Character, 2010, vol. 61, pp. 732-739. doi 10.1016j.matchar.2010. 04.005

39. Montheillet, F., Gilormini, P., and Jonas, J.J., Relation between Axial Stresses and Texture Development during Torsion: A Simplified Theory, Acta Metall., 1985, vol. 33, pp. 705-717. doi 10.1016/0001-6160(85)900 $35-5$

40. Mironov, S., Inagaki, K., Sato, Y.S., and Kokawa, H., Microstructural Evolution of Pure Copper during Friction-Stir Welding, Philos. Mag., 2015, vol. 95, pp. 367381. doi 10.1080/14786435.2015.1006293

41. Mironov, S., Onuma, T., Sato, Y.S., and Kokawa, H., Microstructure Evolution during Friction-Stir Welding of AZ31 Magnesium Alloy, Acta Mater, 2015, vol. 100, pp. 301-312. doi 10.1016/j.actamat.2015.08.066

42. Suhuddin, U.F.H.R., Mironov, S., Sato, Y.S., Kokawa, H., and Lee, C.-W., Grain Structure Evolution during Friction-Stir Welding of AZ31 Magnesium Alloy, Acta Mater., 2009, vol. 57, pp. 5406-5418. doi 10.1016j. actamat.2009.07.041
43. Feng, A.H. and Ma, Z.Y., Microstructural Evolution of Cast $\mathrm{Mg}-\mathrm{Al}-\mathrm{Zn}$ during Friction Stir Processing and Subsequent Aging, Acta Mater, 2009, vol. 57, pp. 42484260. doi 10.1016/j.actamat.2009.05.022

44. Chen, J., Fujii, H., Sun, Y., Morisada, Y., Kondoh, K., and Hashimoto, K., Effect of Grain Size on the Microstructure and Mechanical Properties of Friction Stir Welded Non-Combustive Magnesium Alloys, Mater Sci. Eng. A, 2012, vol. 549, pp. 176-184. doi 10.1016/j. msea.2012.04.030

45. Mironov, S., Yang, Q., Takahashi, H., Takahashi, I., Okamoto, K., Sato, Y.S., and Kokawa, H., Specific Character of Material Flow in Near-Surface Layer during Friction Stir Processing of AZ31 Magnesium Alloy, Metall. Mater: Trans. A, 2010, vol. 41, pp. 1016-1024. doi 10.1007/s11661-009-0158-X

46. Mironov, S., Motohashi, Y., Kaibyshev, R., Somekawa, H., Mukai, T., and Tsuzaki, K., Development of FineGrained Structure Caused by Friction Stir Welding Process of a ZK60A Magnesium Alloy, Mater. Trans., 2009, vol. 50, pp. 610-617. doi 10.2320matertrans.MRA200 8192

47. Chai, F., Zhang, D., Li, Y., and Zhang, W., Microstructure Evolution and Mechanical Properties of a Submerged Friction-Stir-Processed AZ91 Magnesium Alloy, J. Mater. Sci., 2015, vol. 50, pp. 3212-3225. doi 10.1007/ s10853-015-8887-2

48. Mironov, S., Sato, Y.S., and Kokawa, H., Development of Grain Structure during Friction Stir Welding of Pure Titanium, Acta Mater, 2009, vol. 57, pp. 4519-4528. doi 10.1016/j.actamat.2009.06.020

49. Sato, Y.S., Nagahama, Y., Mironov, S., Kokawa, H., Park, S.H.C., and Hirano, S., Microstructural Studies of Friction Stir Welded Zircaloy-4, Scripta Mater, 2012, vol. 67, pp. 241-244. doi 10.1016/j.scriptamat.2012. 04.029 